\title{
TECNOLOGIA ASSISTIVA: DEFINIÇÃO, DESCRIÇÃO E APLICAÇÃO
}

\author{
Eduardo José MANZINI ${ }^{1}$
}

COOK, Albert M.; POLGAR, Jan Miller. Cook \& Hussey's A ssistive Technologies: principles and practices. 3. ed. St. Louis: Mosby Elsevier, 2008.

A terceira edição da obra de Cook e Polgar é uma versão ampliada e atualizada sobre o tema tecnologia assistiva. O livro, ainda não traduzido, está na língua inglesa, conta com 571 páginas, apresenta um glossário para que o leitor possa familiarizar-se com o tema e finaliza com um val ioso índice remissivo de assuntos.

N os capítul os iniciais, os autores contextual izam a tecnologia assistiva e o lugar ocupado por ela no quadro legislativo dos Estados Unidos, no quadro industrial eos avanços do tema na pesquisa científica. Logo de entrada, épossível perceber a importância da tecnologia assistiva e como ela deverá crescer ainda mais nos próximos anos. Também são tecidas considerações conceituais sobre os assunto. Essas conceituações e definições dão o tom do livro, ou seja, a cada novo capitulo é apresentada a definição dos termos utilizados.

A obra, dividida em cinco partes, aborda desde os objetivos gerais da tecnologia assistiva, as áreas cobertas por ela, até o contexto de aplicação.

O leitor poderá encontrar grande variedade de subtemas em tecnologia assistiva, tais como:

1) equipamentos e ajudas sensoriais para pessoas com deficiência visual, auditiva e física;

2) sistemas de comunicação alternativa;

3) recursos e equipamentos para mobilidade e transporte;

\footnotetext{
${ }^{1}$ Docente do Depto. de Educação Especial e do Programa de Pós-graduação em Educação da Unesp de Marília, São Paulo, Brasil. 
MANZINI, E. J.

4) seating (estudos sobre a postura sentada);

5) recursos para controle de ambientes;

6) tecnologia assistiva no contexto escolar;

7) tecnologia assistiva no contexto do trabalho;

Os capítulos trazem fotos, esquemas e figuras que permitem, numa linguagem clara e objetiva, boa compreensão sobre os conceitos, recursos e equipamentos de tecnologia assistiva.

Sem dúvida, para quem trabalha com pessoas com deficiência, esta obra irá auxiliar na compreensão das interfaces entre tecnologia e ser humano. 